\title{
Soldagem de um Aço Inoxidável Ferrítico com o Processo A-TIG
}

\author{
(Ferritic Stainless Steel Welding with the A-TIG Process)
}

\author{
Alessandra Gois Luciano de Azevedo ${ }^{1}$, Valtair Antonio Ferraresi ${ }^{1}$, Jesualdo Pereira Farias ${ }^{2}$ \\ ${ }^{1}$ Universidade Federal de Uberlândia, Faculdade de Engenharia Mecânica, Av. João Naves de Ávila, n 2121, CEP 38400-902, \\ Laboratório de Soldagem (Laprosolda) valtairf@mecanica.ufu.br \\ ${ }^{2}$ Universidade Federal do Ceará, Departamento de Engenharia Metalúrgica e Materiais, Campus do Pici, Bloco 715, Laboratório de \\ Soldagem (Engesolda),Fortaleza-CE.Cep: 60488-760.jpf@secrel.com.br
}

\begin{abstract}
Resumo
O processo de soldagem TIG com fluxo (processo A-TIG) apresenta como principal vantagem a possibilidade de se obter uma maior penetração do cordão de solda empregando os mesmos parâmetros de soldagem do processo TIG convencional. Diversos estudos mostram a influência dos fluxos ativos sobre as características geométricas das soldas em aços inoxidáveis austeníticos, porém pouco se sabe sobre a influência deste processo nas características geométricas e metalúrgicas de cordões de solda em aços inoxidáveis ferríticos. Neste trabalho são aplicados diferentes tipos de fluxo na soldagem de aço inoxidável ferrítico com o objetivo de verificar possiveis influências no perfil do cordão de solda, no seu aspecto visual, na microestrutura, na dureza da zona fundida e na resistência ao impacto (ensaio Charpy). As soldagens "bead-on-plate" foram realizadas sem metal de adição. Foram utilizados seis tipos de fluxo, sendo um óxido elaborado em laboratório $\left(\mathrm{TiO}_{2}\right)$ e cinco fluxos comerciais. Os resultados mostraram que a utilização do fluxo permite um aumento na penetração com mudanças significativas no aspecto do cordão de solda. Verificou-se ainda que a microestrutura e a dureza do cordão de solda do aço estudado não foram afetadas pelo tipo de fluxo utilizado, com a microestrutura analisada em microscópio óptico. $O$ aço em estudo mostrou um alto grau de fragilidade à temperatura ambiente.
\end{abstract}

Palavras-chave: processo A-TIG, fluxo ativo, microestrutura, tenacidade.

\begin{abstract}
The A-TIG welding process presents as main advantage the possibility of increase in the penetration depth using the same parameters as conventional TIG welding. Many researchers show the influence of the active flux on the weld geometry in austenitic stainless steel, however little it is known of the influence of this process in the weld fillet shape and metallurgic characteristics of the weld fillet in ferritic stainless steel. In this work different types of flux are applied with the objective to verify possible influences on the weld fillet in ferritic stainless steel welding, such its visual aspect, the microstructure, the hardness and resistance to the impact of the fusion zone. Bead on plate welds were made without metal filler. Six types of flux had been used, and one flux was prepared in laboratory $\left(\mathrm{TiO}_{2}\right)$ and the others five were commercial flux. The results indicate that the use of the flux allows increase in the penetration with significant changes in the aspect of the weld fillet. It was verified that the microstructure and the hardness of the weld fillet of this ferritic stainless steel was not been affected by the flux type. The result of the Charpy test in the metal base it was batter in the fusion zone
\end{abstract}

Key words: welding A-TIG, active flux, microstructure, tenacity.

\section{Introdução}

Com o objetivo de aumentar a produtividade da soldagem pelo processo TIG o "Paton Welding Institute" apresentou na primeira metade dos anos 60 a técnica chamada de A-TIG (soldagem TIG com fluxo ativo), que consiste em se depositar uma fina camada de um fluxo com solvente (acetona ou álcool) sobre a superfície da peça antes da soldagem. A deposição da camada é feita através de um pincel, ou por "spray", após a

(Recebido em 30/07/2008; Texto Final em 11/12/2008). secagem é realizada a soldagem. Resultados experimentais da época demonstraram que a produtividade do processo A-TIG poderia ser aumentada em até 3 vezes em relação ao processo TIG convencional [1,2]. Marya [1] cita que durante a soldagem o calor do arco funde e vaporiza a camada de fluxo produzindo alterações na poça de fusão e no arco elétrico, podendo produzir um aumento na penetração.

Na soldagem com fluxo ativo, recomenda-se que a camada apresente uma espessura uniforme para assegurar a repetibilidade dos resultados, além de uma boa aderência ao material de base para suportar a força do arco durante a soldagem [1]. A principal desvantagem desta técnica reside principalmente na propensão à formação de escória sobre a superfície da solda, levando a um acabamento superficial ruim. No caso da soldagem em vários 
passes, a escória formada deve ser adequadamente retirada para evitar a possibilidade da ocorrência de inclusões em passes subseqüentes. Não se pode também desconsiderar a possibilidade de contaminação ou fragilização do metal de solda em função das interações entre o fluxo e o metal fundido [2].

Richetti e Ferraresi [3] aplicaram o fluxo ativo de tal forma a obter soldas com bom acabamento superficial, reduzindo a quantidade de escória formada. Ao invés de uma camada que cobre toda a superfície da chapa, foram feitas duas faixas de fluxo, separadas por uma distância predeterminada. Desta forma, a camada de fluxo isolou eletricamente certas regiões da superfície da peça direcionando a região de incidência do arco para o centro da junta. Esta técnica foi chamada de Técnica da Constrição Direcionada (TCD).

Muitos mecanismos foram propostos para explicar o aumento da penetração na soldagem A-TIG. Alguns autores $[4,5$ e 6$]$ acreditam que isto ocorre devido ao fato de que as moléculas do fluxo dissociadas pelo intenso calor gerado serem capazes de capturar elétrons nas regiões periféricas do arco (mais frias), formando ali íons negativos. A captura de elétrons por parte destes elementos reduz a densidade periférica de elétrons livres no arco e, desta forma, o principal canal condutor de eletricidade é reduzido, resultando num efeito de constrição (redução do diâmetro da coluna do arco). Ao mesmo tempo, este efeito de constrição induz um aumento na temperatura e na pressão do arco, permitindo aumentar significativamente a penetração da solda.

Um outro mecanismo sugerido para o aumento da penetração na soldagem com fluxo ativo está relacionado a modificações microquímica da poça de fusão pela adição de elementos do fluxo. Essas modificações causam uma inversão no gradiente de tensão superficial, gerando um fluxo de convecção (também chamado de fluxo de Marangoni) no sentido inverso ao que ocorre normalmente na soldagem TIG. O fluxo de convecção gerado flui das extremidades para o centro da poça, causando uma redução na largura e um aumento na penetração [4].

A maior dificuldade desta técnica está na seleção de um fluxo para uma determinada aplicação (material), isto recai principalmente sobre a não divulgação da sua composição química, a qual normalmente é considerada como um segredo industrial. A falta de informações técnicas também pode contribuir para um aumento desta dificuldade, por exemplo, na obtenção de dados qualitativos ou quantitativos a respeito do efeito dos fluxos sobre a composição química da solda, ou sobre suas propriedades mecânicas [7]. Entretanto, Perry et al. [4] citam que diferentes revestimentos a base de óxidos, sais alcalinos, halogênios, ou fluoretos têm sido reportados no passado como apresentando um efeito favorável sobre a penetração da solda. Por exemplo, um revestimento a base de óxidos de ferro, cromo, silício, titânio, manganês, níquel, cobalto, molibdênio e cálcio (misturados ou não) têm sido usados para melhorar a soldabilidade e aumentar a velocidade de soldagem em aços inoxidáveis. Evidentemente, a composição do fluxo também pode ser acertada para melhorar as propriedades mecânicas do metal de solda em relação às soldas convencionais através da adição de elementos de liga.

Os aços inoxidáveis ferríticos apresentam uma baixa soldabilidade (comparados com os aços inoxidáveis austeníticos), pois a sua solda é caracterizada por ductilidade e tenacidade baixas. Estes problemas de soldabilidade têm limitado, até recentemente, a aplicabilidade destes aços em estruturas soldadas. Recentemente, desenvolveram-se aços inoxidáveis ferríticos com inserção de teores de níquel e/ou titânio, os quais melhoram suas características mecânicas. Sua solidificação poderá ser $100 \%$ ferrita, no entanto, na soldagem desses materiais, dependendo do balanço entre os elementos estabilizadores da ferrita, existe a possibilidade de formação de austenita, que no resfriamento pode se transforma em martensita [8].

Neste trabalho será utilizado o processo A-TIG na soldagem de chapas de aço inoxidável ferrítico com o objetivo de analisar a influência de seis tipos de fluxo sobre a geometria do cordão de solda, comparando com o processo TIG convencional. Destes fluxos, foram escolhidos três para a análise da resistência ao impacto e microdureza, todos na zona fundida.

\section{Materiais e Métodos}

Em todos os ensaios foi utilizada uma fonte de soldagem eletrônica multiprocesso. As soldagens foram realizadas de forma mecanizada empregando intensidade de corrente de $200 \mathrm{~A}$, velocidade de soldagem de $3,5 \mathrm{~mm} / \mathrm{s}$, distância da ponta do eletrodo a peça foi de $2,0 \mathrm{~mm}$, eletrodo de tungstênio AWS EWTh-2 com diâmetro de 3,2 mm e ângulo de apontamento de $60^{\circ}$. Como gás de proteção utilizou-se argônio com uma vazão de $14 \mathrm{l} / \mathrm{min}$. Estes parâmetros foram obtidos a partir de testes preliminares.

Utilizou-se como metal de base chapa de aço inoxidável ferrítico cuja composição química está apresentada na Tabela 1. É um aço inoxidável ferrítico, desenvolvido para fornecer uma alternativa ao aço carbono e uma opção econômica de substituição aos aços inoxidáveis convencionais (principalmente os austeníticos) onde as condições de corrosão não justificam a especificação de um aço mais nobre. A empresa fabricante deste material indica a sua utilização em estruturas, principalmente a veicular (ônibus) e em equipamentos industriais, como mesas alimentadoras e difusores de usinas de cana-de-açúcar por apresentar boa resistência à abrasão úmida. Este material apresenta um limite de resistência de $480 \mathrm{MPa}$, limite de escoamento de $380 \mathrm{MPa}$ e alongamento de $28 \%$.

Para análise das características geométricas e aspecto do cordão de solda os fluxos foram aplicados somente na metade de cada chapa, obtendo-se desta forma, uma parte do cordão de solda com o processo TIG convencional e uma parte com a aplicação da técnica A-TIG. Para o ensaio Charpy a soldagem foi realizada "bead-on-plate" nas dimensões de 250 × 30 × 6,35 mm e em juntas de topo. Foi empregado o ensaio Charpy reduzido na zona fundida, conforme Norma ASTM E23-04 (dimensões do corpo de prova de $5 \times 10 \times 55 \mathrm{~mm}$ ). A junta foi soldada dos dois lados (dois passes) para a obtenção de uma penetração adequada ao ensaio. 
Tabela 1. Composição química do aço inoxidável ferrítico.

\begin{tabular}{l|c|c|c|c|c|c|c}
\hline Elemento & $\mathrm{C}$ & $\mathrm{Mn}$ & $\mathrm{Si}$ & $\mathrm{Cr}$ & $\mathrm{Ni}$ & $\mathrm{P}$ & $\mathrm{S}$ \\
\hline \% em peso & 0.015 & 0.59 & 0.47 & 11.02 & 0.35 & 0.021 & 0.001 \\
\hline Elemento & $\mathrm{Mo}$ & $\mathrm{V}$ & $\mathrm{Al}$ & $\mathrm{Co}$ & $\mathrm{Nb}$ & $\mathrm{Ti}$ & $\mathrm{Cu}$ \\
\hline \% em peso & 0.017 & 0.025 & 0.002 & 0.02 & 0.015 & 0.011 & 0.024 \\
\hline
\end{tabular}

Com o intuito de comparar o efeito do fluxo sobre as características geométricas do cordão de solda foram empregados seis tipos de fluxo ativo, designados da seguinte maneira: fluxo A - dióxido de titânio; fluxo B (fluxo comercial americano) e fluxos C, D, E e F (fluxos comerciais europeus). O óxido de titânio foi utilizado por ser citado na literatura como adequado para emprego como fluxo ativo. As composições dos fluxos comerciais não foram fornecidas pelos fabricantes. Os fluxos foram misturados com acetona e aplicados na superfície a ser soldada com ajuda de um pincel, com exceção do fluxo C por ser "spray".

De cada corpo de prova soldado foram retiradas amostras da seção transversal do cordão de solda, no centro do cordão da região de interesse (região sem e com fluxo). Foram obtidas medidas geométricas da seção transversal do cordão de solda e medidas de microdureza e análise de microestrutra no centro da zona fundida do cordão de solda (seção transversal). Para estas análises foi empregado o reagente Villela.

Para melhorar o aspecto do cordão de solda e minimizar a quantidade de escória formada na superfície foi realizada soldagem com as mesmas condições acima com a técnica TCD. Esta técnica foi utilizada também para a confecção dos corpos de prova do Ensaio Charpy, onde foram utilizados os fluxos A, $\mathrm{B}$ e C, pela facilidade de obtenção.

\section{Resultados e Discussões}

\subsection{Aspecto dos Cordões de Solda}

A Figura 1 apresenta o aspecto superficial dos cordões de solda. Do lado direito de cada corpo de prova encontra-se o cordão sem fluxo, ou seja, soldagem TIG convencional e do lado esquerdo está a continuidade do cordão obtido com os diferentes tipos de fluxos. Observando os cordões com a aplicação do fluxo (Figura 1) é possível perceber que todas as regiões dos cordões com fluxo ativo apresentaram aspecto oxidado (escória), porém, os fluxos B, D e E apresentaram cordões mais lisos, uniformes e com aspecto menos oxidado do que os $\mathrm{A}, \mathrm{C}$ e $\mathrm{F}$. O fluxo $\mathrm{C}$ foi o que apresentou o pior aspecto superficial.

\subsection{Perfil dos Cordões de Solda}

Foi realizado um corte na seção transversal dos corpos de prova para a avaliação das características geométricas do cordão de solda. Foram medidas a largura, a penetração e a área da zona fundida de apenas uma seção do corpo de prova de cada tipo de fluxo utilizado. Os resultados obtidos encontram-se na Tabela 2. Verifica-se que o fluxo $\mathrm{C}$ foi o que apresentou maior penetração, menor largura e maior área fundida. Os fluxos $\mathrm{A}\left(\mathrm{TiO}_{2}\right), \mathrm{D}$ e E não apresentaram ganhos em termos de penetração comparandose com a soldagem sem fluxo, apesar de mudanças ocorridas na largura do cordão.

As Figuras 2 e 3 mostram a seção transversal dos cordões de solda obtidos da soldagem dos corpos de prova realizados sem e com adição de fluxo, respectivamente. Comparando as Figuras 2 e 3, é possível ter uma visão global do perfil do cordão de solda com a aplicação de cada tipo de fluxo.

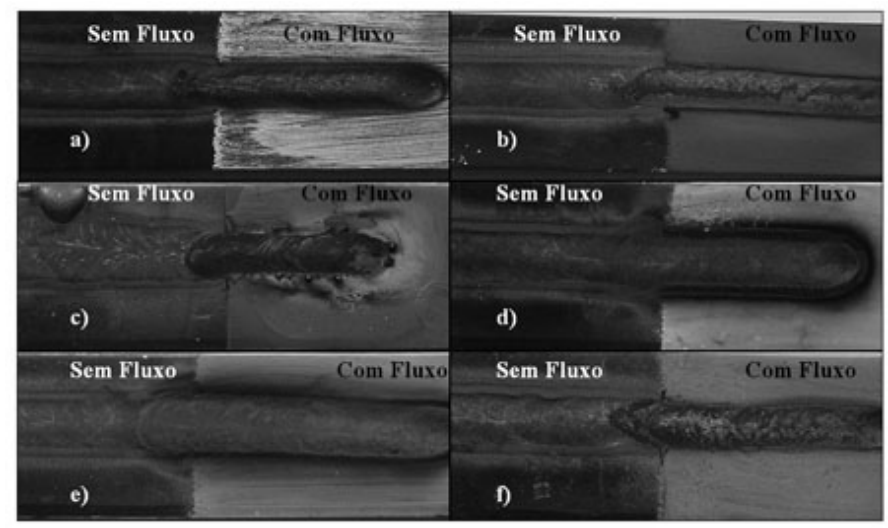

Figura 1. Aspecto visual dos cordões de solda. Fluxos: a) A; b) c) C; d) D; e) E; f) F.

Tabela 2. Medidas geométricas.

\begin{tabular}{c|c|c|c}
\hline Corpo de prova & Penetração $(\mathbf{m m})$ & Largura $\mathbf{( m m})$ & Área Fundida $\mathbf{( m m}^{\mathbf{2}} \mathbf{~}$ \\
\hline Sem fluxo & 3,1 & 12,1 & 23,3 \\
\hline Fluxo A & 3,1 & 9,4 & 19,3 \\
\hline Fluxo B & 4,3 & 8,5 & 22,2 \\
\hline Fluxo C & 4,7 & 7,7 & 28,8 \\
\hline Fluxo D & 3,1 & 9,1 & 21,2 \\
\hline Fluxo E & 2,8 & 10,3 & 21,0 \\
\hline Fluxo F & 4,5 & 8,1 & 23,2 \\
\hline
\end{tabular}


Com base em dados da literatura $[4,5$ e 6$]$, principalmente para aços inoxidáveis austeníticos, esperavam-se maiores valores de penetração para a soldagem do aço inoxidável ferrítico com fluxo. Um dos problemas que pode ter contribuído para este comportamento, apesar dos cuidados tomados no momento da aplicação, está relacionado à homogeneidade da camada de fluxo e/ou uma fraca aderência do fluxo na chapa. Outro ponto pode estar relacionada a composição química entre metal de base com o tipo de fluxo utilizado, não gerando a convecção do fluxo (fluxo de Marangoni) como esperado. Além disso, existem também os parâmetros de soldagem, pois na literatura observa-se o emprego de correntes de soldagem mais baixas do que a empregada neste trabalho. Marya [1] empregando a TCD observou que a penetração tende a aumentar para as soldagens realizadas com correntes mais baixas. Deverá ser feita uma análise futura para esclarecer melhor este fato.

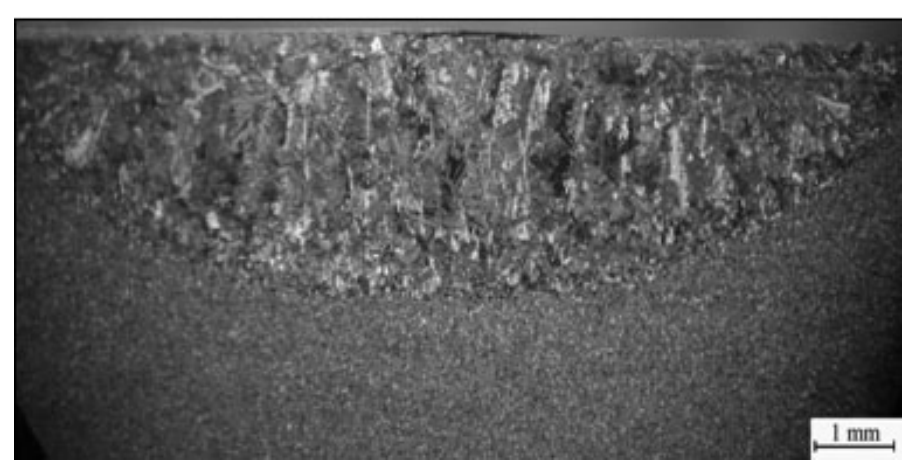

Figura 2. Perfil do cordão de solda do corpo de prova sem fluxo ativo.
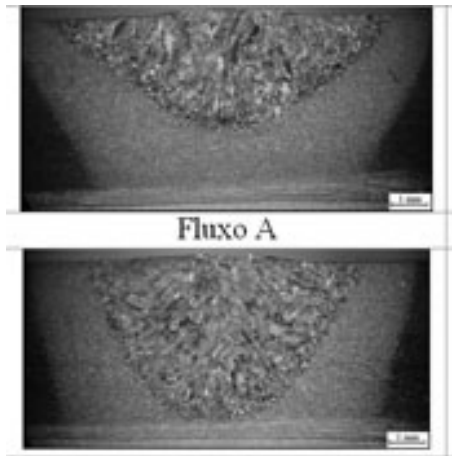

Fluxo C

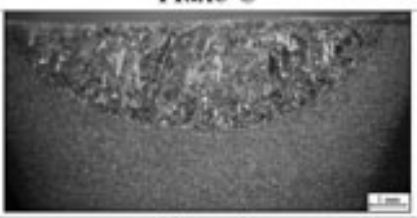

Fluxo E

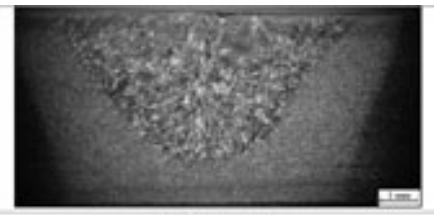

Fluxo B

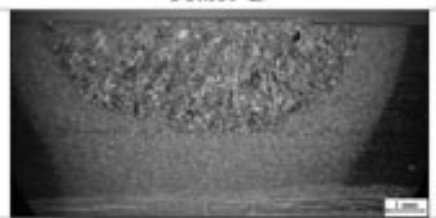

Fluxo D

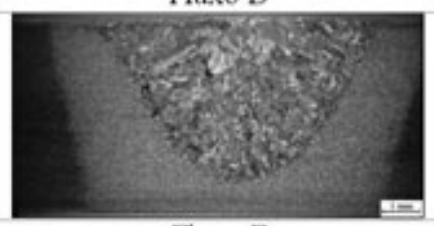

Fluxo F
Figura 3. Perfis dos cordões de solda empregando os diferentes tipos de fluxo mostrados na Tabela 2.

\subsection{Medidas de Microdureza na Zona Fundida}

Foram realizadas 10 medidas de microdureza Vickers na região central da zona fundida de cada cordão de solda. Os resultados estão descritos na Tabela 3.

Tabela 3. Microdureza da zona fundida $\left(\mathrm{HV}_{0,1}\right)$

\begin{tabular}{|c|c|c|c|c|c|c|c|}
\hline Medidas & Sem fluxo. & Fluxo A & Fluxo B & Fluxo C & Fluxo D & Fluxo E & Fluxo F \\
\hline 1 & 291 & 334 & 314 & 317 & 304 & 375 & 330 \\
\hline 2 & 319 & 324 & 281 & 239 & 288 & 288 & 298 \\
\hline 3 & 327 & 319 & 337 & 178 & 281 & 363 & 320 \\
\hline 4 & 288 & 354 & 295 & 319 & 300 & 296 & 312 \\
\hline 5 & 302 & 339 & 311 & 275 & 291 & 268 & 288 \\
\hline 6 & 273 & 367 & 313 & 313 & 287 & 343 & 175 \\
\hline 7 & 339 & 334 & 334 & 272 & 308 & 334 & 298 \\
\hline 8 & 318 & 352 & 249 & 246 & 279 & 328 & 330 \\
\hline 9 & 307 & 320 & 191 & 323 & 279 & 325 & 322 \\
\hline 10 & 271 & 324 & 320 & 260 & 307 & 297 & 279 \\
\hline Média & $\mathbf{3 0 3 , 5}$ & $\mathbf{3 3 6 , 7}$ & $\mathbf{2 9 4 , 5}$ & $\mathbf{2 7 4 , 2}$ & $\mathbf{2 9 2 , 4}$ & $\mathbf{3 2 1 , 7}$ & $\mathbf{2 9 5 , 2}$ \\
\hline Desvio & $\mathbf{2 2 , 7}$ & $\mathbf{1 6 , 3}$ & $\mathbf{4 4 , 7}$ & $\mathbf{4 6 , 2}$ & $\mathbf{1 1 , 5}$ & $\mathbf{3 4 , 1}$ & $\mathbf{4 5 , 7}$ \\
\hline
\end{tabular}

A Figura 4 apresenta os resultados na forma de gráfico, onde é possível verificar que a dureza da zona fundida ficou dentro de uma faixa entre $274,2 \mathrm{HV}$ a $336,7 \mathrm{HV}$. Valores estes bem acima da dureza do metal de base. A dureza média do material como recebido foi de $140 \mathrm{HV}$ e tamanho de grãos médio ASTM 10. Este maior aumento está relacionada a sua microestrura, no metal de base é somente ferrita enquanto que na zona fundida é ferrita e martensita.
Com os resultados apresentados na Figura 4 é possível citar que a aplicação da soldagem A-TIG com vários tipos de fluxos não apresentou influência significativa na zona fundida para as condições de ensaios utilizados. Apesar de serem observadas pequenas variações nas medidas de durezas, estas podem ser explicadas pela heterogeneidade presente na zona fundida, isto é, diferentes microestruturas desta zona. 


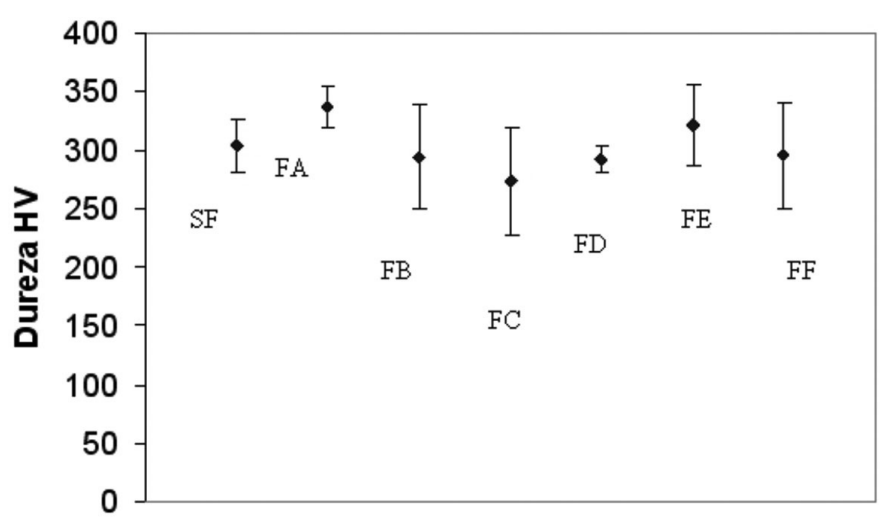

Tipos de fluxo

Figura 4. Variação da dureza com o tipo de fluxo do processo A-TIG (SF - Sem Fluxo, FA - Fluxo A, FB - Fluxo B, FC Fluxo C, FD - fluxo D, FE - Fluxo E e FF - Fluxo F).

\subsection{Metalografia da Zona Fundida}

Com a composição química do aço fornecida pelo fabricante é possível através do Diagrama de Schaeffler prever a microestrutura da zona fundida [9]. Para isso, os equivalentes de cromo e níquel e devem ser calculados, através das equações: $\mathrm{Cr}_{\text {eq }}=\% \mathrm{Cr}+\% \mathrm{Mo}+1,5 \% \mathrm{Si}+0,5 \% \mathrm{Nb}$ e Ni${ }_{\text {eq }}=\% \mathrm{Ni}+30 \% \mathrm{C}$ $+0,5 \% \mathrm{Mn}$. Com isso, os valores obtidos são: $\mathrm{Cr}_{\mathrm{eq}}=11,72 \mathrm{e}$ $\mathrm{Ni}_{\text {eq }}=1,095$. Com esses dados e com o diagrama de Schaeffler verifica-se que o aço fica no limite entre uma estrutura 100\% ferrítica e o início de formação da martensitica.

Balmfort e Lippold [10] propuseram um diagrama específico para a região de ferrita e martensita, sendo particularmente útil para avaliar a microestrutura da zona fundida de aços inoxidáveis ferríticos e matensíticos. As fórmulas empíricas para esta análise são: $\mathrm{Cr}_{\text {eq. }}=\% \mathrm{Cr}+2 \% \mathrm{Mo}+10(\% \mathrm{Al}+\% \mathrm{Ti})$ e $\mathrm{Ni}_{\text {eq }}=\% \mathrm{Ni}+$ $35 \% \mathrm{C}+20 \% \mathrm{~N}$. Com esta formulação os valores obtidos são: $\mathrm{Cr}_{\text {eq }} \cdot=11,346$ e Nieq. $=0,875$. Com esses dados e o diagrama apresentado pelos autores acima se chega que a quantidade de ferrita na zona fundida do aço (processo TIG autógena) é de aproximadamente $30 \%$ e com o restante de $70 \%$ de martensita.

A Figura 5(a) mostra a miscroestrutura do material como recebido e a Figura 5(b) mostra a microestrutura da zona fundida soldada sem a presença de fluxo. A Figura 6 mostra as microestruturas da zona fundida com a presença de fluxos durante a soldagem. Em todos os casos é possível verificar que a microestrutura formada é de martensita e ferrita (região clara).

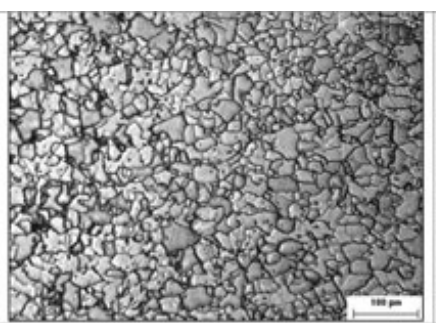

(a) - metal de base

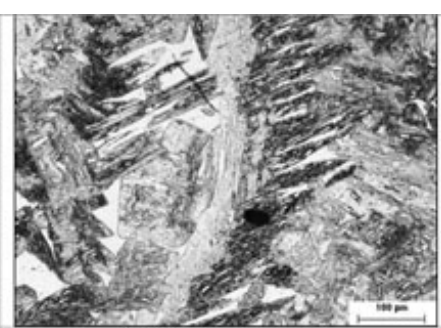

(b) Zona Fundida
Figura 5. Microestrutura do metal de base e da zona fundida.

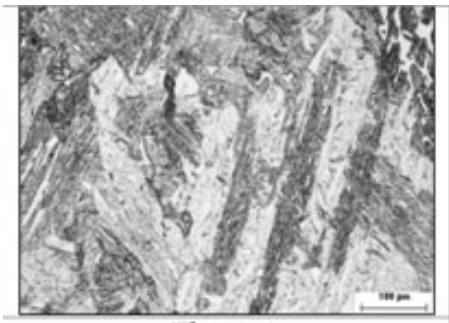

Fluxo A

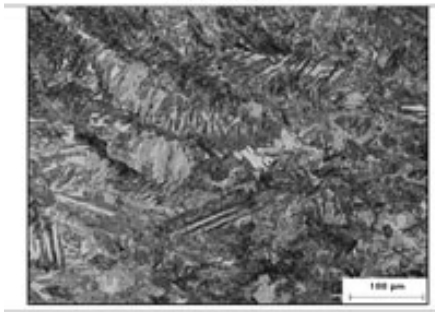

Fluxo C

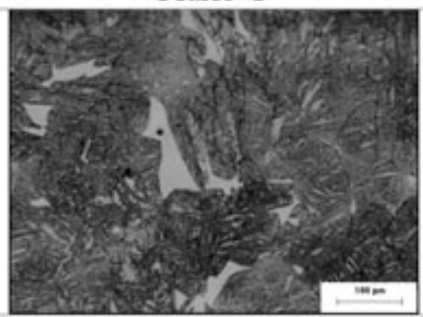

Fluxo E

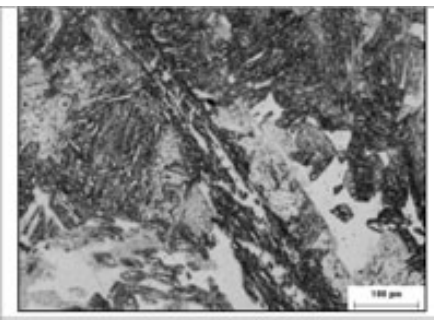

Fluxo B

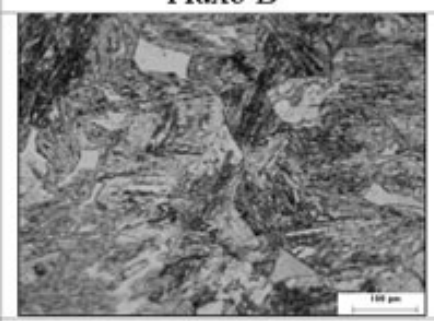

Fluxo D

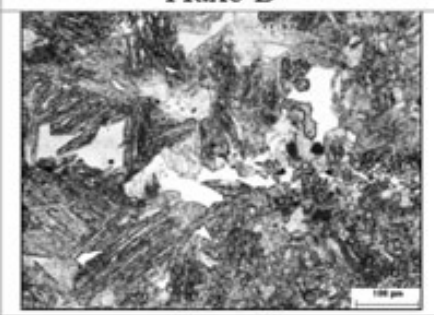

Fluxo F
Figura 6. Microestruturas dos cordões de solda na zona fundida de cada corpo de prova.

\subsection{Técnica da Constrição Direcionada (TCD)}

Para poder tirar proveito da técnica A-TIG, Richetti e Ferraresi [3] propuseram uma forma de aplicação desta camada de fluxo com o objetivo de obter cordões de solda com bom acabamento superficial e redução da quantidade de escória formada. Esta forma de aplicação do fluxo foi chamada de Técnica de Constrição Direcionada (TCD), onde o fluxo é aplicado na junta em duas faixas separadas por uma distância predeterminada do centro da junta, chamada de parâmetro "a". Este procedimento é ilustrado esquematicamente na Figura 7. As condições de soldagem foram realizadas em uma junta com o parâmetro "a" de 6,0 mm e com os mesmos parâmetros dos testes realizados acima. Para a realização destes testes foram utilizados apenas os fluxos A, B e C.

Para estes testes a penetração do cordão de solda com a aplicação do Fluxo A foi de 3,65 mm; com o Fluxo B foi de 4,27 $\mathrm{mm}$ e com o Fluxo $\mathrm{C}$ foi de 4,06 $\mathrm{mm}$. Comparando estes valores com os mesmos tipos de fluxo da Tabela 2 verifica-se que ocorreu uma pequena variação na penetração. Isto demonstra que esta técnica não influencia de forma significativa a penetração do cordão de solda.

A Figura 7(b) mostra o aspecto do cordão para o fluxo A utilizando a técnica de constrição direcionada. É possível verificar que existe uma melhoria no aspecto do cordão e um menor nível de escória formada, comparada com a Figura 1(a). O mesmo fenômeno foi observado para os outros fluxos utilizados. 


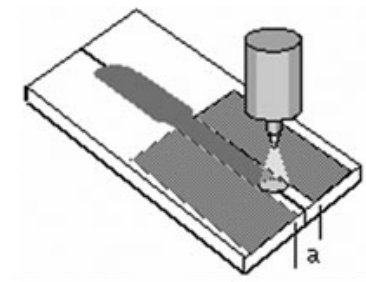

(a)

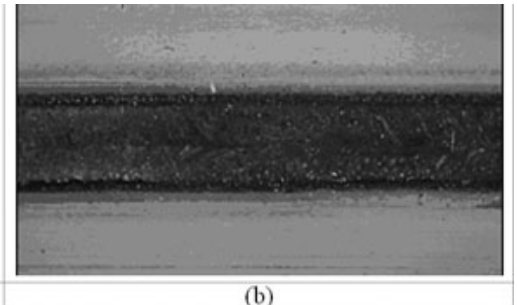

(b)
Figura 7. (a) Procedimento proposto para aplicação da camada de fluxo ativo; (b) Aspecto do cordão de solda com a técnica TCD para o Fluxo A.

\subsection{Resultados do Ensaio Charpy na Zona Fundida}

Foram realizados testes de impacto Charpy-V reduzido na zona fundida à temperatura ambiente com o objetivo de verificar a resistência ao impacto do aço em estudo com a soldagem TIG convencional e com o processo A-TIG. Foram soldados sete corpos de prova, empregando-se três tipos de fluxo (A, B e C) e duas técnicas de aplicação de fluxo sobre a superfície da junta, sendo a primeira o processo A-TIG convencional, onde o fluxo é aplicado em toda a superfície da junta que entra em contato com o arco elétrico e a segunda a técnica TCD. Foi realizado também teste em uma junta soldada sem a aplicação de fluxo ativo. As condições de soldagem estão apresentadas na Tabela 4. Foi utilizada uma maior corrente de soldagem para o ensaio sem fluxo para garantir a penetração total na junta proposta, pois a análise é realizada na zona fundida do cordão.

De cada corpo de prova soldado foram retiradas cinco amostras para a realização do ensaio Charpy reduzido. Destas amostras foram descartados o valor maior e o menor para a obtenção da média. A Tabela 5 apresenta os resultados com o valor médio e desvio padrão.

Tabela 4. Parâmetros de soldagem dos corpos de prova do ensaio charpy.

\begin{tabular}{l|l|l}
\hline & Testes com fluxo & Teste sem fluxo \\
\hline Corrente de soldagem $(\mathrm{A})$ & 200 & 300 \\
\hline Velocidade de soldagem $(\mathrm{cm} / \mathrm{min})$ & 20 & 20 \\
\hline Gás de proteção $(\mathrm{Ar})(\mathrm{l} / \mathrm{min})$ & 14 & 14 \\
\hline $\begin{array}{l}\text { Eletrodo - especificação, } \phi(\mathrm{mm}) \text { e ângulo } \\
\text { de apontamento }\end{array}$ & EWTh-2, 3.2 e $60^{\circ}$ & EWTh-2, 3.2 e $60^{\circ}$ \\
\hline Ângulo da tocha & $90^{\circ}$ com a horizontal & $90^{\circ}$ com a horizontal \\
\hline DEP $(\mathrm{mm})$ & 2,0 & 2,0 \\
\hline Parâmetro "a" $(\mathrm{mm})$ & 6,0 & ---- \\
\hline
\end{tabular}

OBS.: Parâmetro "a” indica a distância entre as faixas de aplicação do fluxo na técnica de constrição direcionada.

Tabela 5. Média e desvio padrão dos ensaios Charpy.

\begin{tabular}{c|c|c|c}
\hline Corpo de prova & Tipo de Fluxo & $\begin{array}{c}\text { Valor médio da } \\
\text { Energia (J) }\end{array}$ & Desvio padrão \\
\hline 1 & Sem fluxo & 3,0 & 0,3 \\
\hline 2 & A (TCD) & 3,7 & 1,1 \\
\hline 3 & A (A-TIG) & 4,1 & 0,8 \\
\hline 4 & B (A-TIG) & 3,7 & 2,2 \\
\hline 5 & B (TCD) & 9,3 & 3,2 \\
\hline 6 & C (A-TIG) & 4,6 & 1,2 \\
\hline 7 & C (TCD) & 4,7 & 1,2 \\
\hline
\end{tabular}

Para uma melhor visualização da influência do fluxo e da técnica de aplicação de fluxo sobre a energia de impacto, montouse o gráfico da Figura 8 que apresenta a média das energias de impacto absorvidas pelos corpos de prova ensaiados juntamente com o desvio padrão.

Como se pode observar na Figura 8, a média da energia de impacto absorvida na zona fundida foi aproximadamente a mesma para todos os corpos de prova realizados com e sem fluxo ativo independente da técnica aplicada, exceto para o de prova 5, onde a média da energia de impacto foi cerca de 3 vezes maior.

Comparando-se os dados da Figura 8 com os dados fornecidos pelo fabricante do material (energia absorvida pelo ensaio Charpy a temperatura ambiente foi de $100 \mathrm{~J}$ ) percebese que o metal de base absorve uma energia muito superior a zona fundida. A baixa energia obtida na zona fundida pode estar relacionada com a microestrura formada nesta região do cordão de solda (grande quantidade de martensita). 


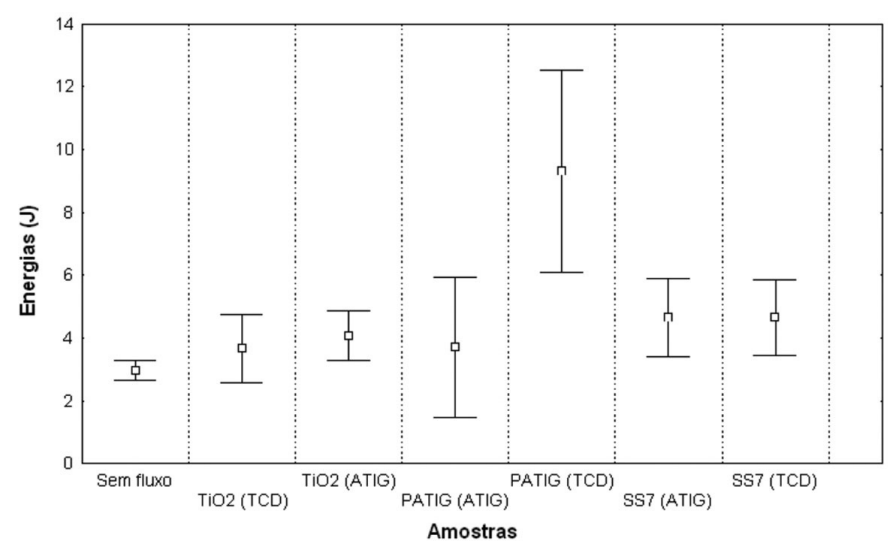

Figura 8. Gráfico das médias das energias do ensaio Charpy com desvio padrão.

A Figura 9 apresenta o aspecto da fratura do ensaio Charpy. Como se pode observar a fratura apresenta planos de clivagem, característica de fratura frágil. Em toda a extensão do corpo de prova foi encontrado o mesmo aspecto de fratura. Os corpos de prova soldados com fluxo ativo, também apresentaram esse tipo de aspecto de fratura por clivagem.

Mesmo com a adição do fluxo ativo a energia de impacto manteve-se bem mais baixa do que a alcançada pelo metal de base nas mesmas condições de ensaio. Como o ensaio foi realizado na zona fundida, uma queda de energia poderia ser esperada devido à formação de martensita observada nesta zona após a soldagem. Entretanto, esta fragilidade do material foi muito superior ao esperado.

O corpo de prova 5 da Tabela 5 (ensaio com o fluxo B) apresentou uma maior energia absorvida ao impacto do que os demais. Isto pode se explicado pelo tipo de fluxo juntamente com a técnica utilizada (técnica TCD), que pode ter acarretado em uma melhora na resistência ao impacto. Entretanto, para comprovar esta análise serão necessários novos ensaios e um aprofundamento na análise microestrutural da zona fundida.

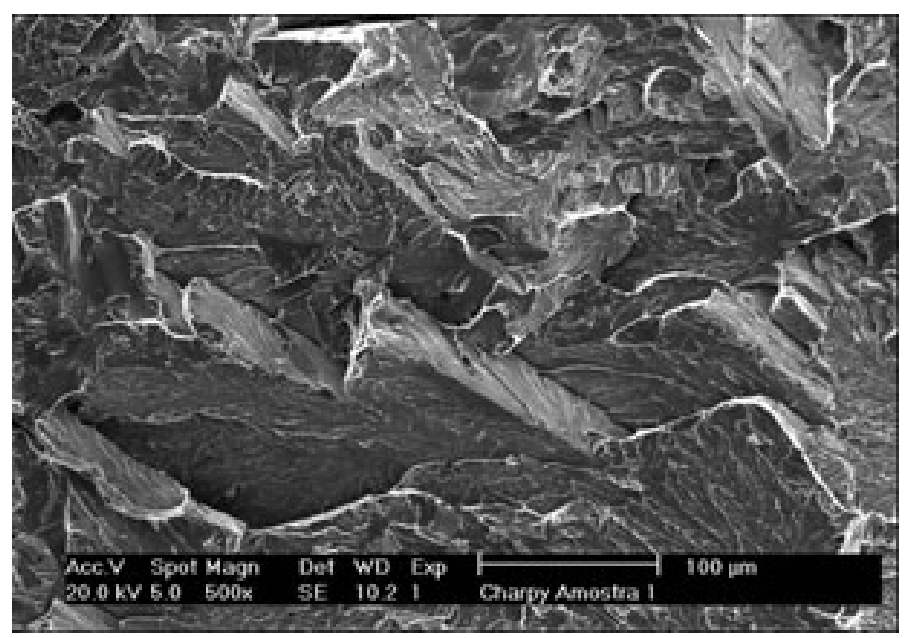

Figura 9. Aspecto de fratura do corpo de prova do ensaio charpy.

\section{Conclusões}

Pelos resultados obtidos neste trabalho verificou-se que a adição de fluxo, comercial ou não, interfere na geometria do cordão, sendo possível obter cordões de maiores penetrações e estreitos.

Os fluxos B, C e F foram os que apresentaram melhores resultados em termo de aumento da penetração do cordão de solda.

Quanto ao aspecto do cordão de solda os fluxos B, D e E apresentaram melhores resultados com uma menor quantidade de escória formada.

Levando em conta a maior penetração e melhor aspecto de cordão de solda o fluxo B foi o melhor.

A técnica de constrição direcionada mantém a penetração observada para o A-TIG convencional, melhora o aspecto do cordão de solda e reduz a quantidade de escória formada.

A microestrutura do cordão de solda, aparentemente, não foi influenciada pela adição ou tipo de fluxo. Em todos os casos a microestrutura formada foi martensita e ferrita.

A dureza da zona fundida não foi influenciada pela adição de fluxo ativo.

Com relação ao ensaio de impacto Charpy não foi observado grandes variações de absorção da energia nos corpos de prova realizados com e sem fluxo ativo, independente da técnica aplicada, exceto para o fluxo B com a técnica TCD, onde a média da energia de impacto foi cerca de 3 vezes maior.

$\mathrm{O}$ material em análise mostrou um alto grau de fragilidade na zona fundida, quando soldado com o processo TIG ("beadon-plate").

\section{Agradecimentos}

Os autores deste trabalho agradecem a FAPEMIG e ao IFM pelo apoio financeiro, a ACELOR-MITTAL pelo fornecimento de material e ao CNPq pela bolsa de pesquisa.

\section{Referências}

[1] MARYA, S. Theoretical and experimental assessment of chloride effects in the A-TIG welding of magnesium. International Institute of Welding Document, Copenhagen, Denmark, 13p. 2002.

[2] PASKELL, T., LUNDIN, C. \& CASTNER, H., GTAW flux increases weld joint penetration. Welding Journal, v.76, n.4, p.57-62, 1997.

[3] RICHETTI, A., FERRARESI, V. A. Aplicação de fluxo ativo na soldagem TIG e Plasma. In.: III COBEF Congresso Brasileiro de Engenharia de Fabricação, Joinvile, SC, Anais do II COBEF, 10p. 2005.

[4] PERrY, N., MARYA, S, and SOUTIF, E. Study and development of flux enhanced GTA penetrations in a commercial grade titanium. In: TRENDS IN WELDING RESEARCH, PROCEEDINGS OF THE 5TH INTERNATIONAL CONFERENCE, Pine Mountain, Georgia, USA, jun.1998, p.520-525.

[5] MIDDEL, W. and DEN OUDEN, G. The Effect of Additives 
on Arc Characteristics in GTA Welding. In: TRENDS IN WELDING RESEARCH, PROCEEDINGS OF THE 5TH INTERNATIONAL CONFERENCE. Pine Mountain, Georgia, USA, jun.1998, p.394-399.

[6] FAN, D., ZHANG, R., GU, Y. \& USHIO, M. Effect of Flux on A-TIG Welding of Mild Steels. Transactions of JWRI (Joining and Welding Research Institute), v.30, n.1, p.35-40, 2001.

[7] LUCAS, W. and HOWSE, D. Activating Flux - Increasing the Performance and Productivity of the TIG and Plasma Processes. Welding \& Metal Fabrication, p.11-17, Jan. 1996.

[8] LIPPOLD LIPPOLD, J. C. and KOTECKI, D. J.: Welding Metallurgy and Weldability of Stainless Steels. John Wiley and Sons, Hoboken, New Jersey, USA. 2005.

[9] MODENESI, P. J., Soldabilidade dos Aços Inoxidáveis. São Paulo, SENAI-SP. p. 21-48. 2001

[10] BALMFORTH, M. C., LIPPOLD, J. C., A new ferriticmartensitic stainless constitution diagram". Welding Journal, n.

(79) 12, p. 339s-345s. 2000. 